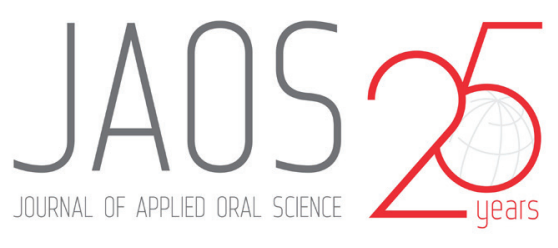

\title{
Effect of photodynamic therapy and non-thermal plasma on root canal filling: analysis of adhesion and sealer penetration
}

\section{Abstract}

Marilia MENEZES ${ }^{1}$

Maíra PRADO 1

Brenda GOMES ${ }^{2}$

Heloisa GUSMAN ${ }^{3}$

Renata SIMÃO ${ }^{1}$
Submitted: September 26, 2016 Modification: November 16, 2016 Accepted: January 9, 2017
Corresponding address: Maíra Prado Cidade Universitária - Centro de Tecnologia. Bloco F, sala F-201 - Ilha do Fundão. Rio de Janeiro - RJ - 21941-972 - Brazil. Phone/Fax: 0055 (21) 3938- 8526 e-mail: maira@metalmat.ufrj.br
Objective: The aim of this study was to evaluate the effect of photodynamic therapy (PDT) and non-thermal plasma (NTP) on adhesion and sealer penetration in root canals. Material and Methods: Sixty singlerooted premolars were used. The teeth were prepared using a crown-down technique. $\mathrm{NaOCl}$ and EDTA were used for irrigation and smear layer removal, respectively. The root canals were divided into three groups: control, PDT, and NTP. After treatments, the roots were filled using gutta-percha and either AH Plus (AHP) or MTA Fillapex (MTAF) sealers. Samples were sectioned at 4,8 , and $12 \mathrm{~mm}$ from the apex (1-mm slices)and analyzed by the push-out bond strength test (adhesion) and confocal laser scanning microscopy (sealer penetration). Data were statistically evaluated using Kruskal-Wallis, Dunn's, and Spearman's tests. Results: Regarding AHP, bond strength was similar in the NTP group and in the control group, but significantly lower in the PDT group. As to MTAF, both therapies showed lower values than the control group. In the confocal analysis of AHP, maximum and mean penetration, and penetrated area were statistically higher in the control group than in the PDT and NTP groups. Penetrated perimeter was similar among groups. Regarding MTAF, all parameters yielded better results in the NTP than in the control group. The PDT and control groups showed similar results except for penetrated area. Conclusion: PDT and plasma therapy affected the adhesion and sealer penetration of root canals filled with AH Plus and MTA Fillapex and there is no positive correlation between adhesion and sealer penetration.

Keywords: Confocal microscopy. Photochemotherapy. Plasma gases. Root canal filling materials.

${ }^{1}$ Universidade Federal do Rio de Janeiro, Departamento de Engenharia Metalúrgica e de Materiais, Rio de Janeiro, RJ, Brasil.

2Universidade Estadual de Campinas, Faculdade de Odontologia de Piracicaba, Departamento de Odontologia Restauradora, Área de Endodontia, Piracicaba, SP, Brasil.

${ }^{3}$ Universidade Federal do Rio de Janeiro, Departamento de Clínica Odontológica, Área de Endodontia, Rio de Janeiro, RJ, Brasil. 


\section{Introduction}

The basic requirements for root canal treatment are effective chemomechanical preparation and threedimensional obturation of the root canal system ${ }^{1}$. The complexity of the root canal system, with isthmuses, ramifications, and dentinal tubules, makes it impossible to eliminate microorganisms from root canals during preparation ${ }^{24}$. In addition to the routinely used chemical substances and instruments, other technologies have been proposed to promote antimicrobial activity in the root canal system, such as photoactivated disinfection and non-thermal plasma7,15,20,27,28.

Root canal obturation is a very important step for a successful treatment. The use of gutta-percha with various root canal sealers is the most common obturation method. AH Plus sealer (Dentsply Maillefer, Ballaigues, Switzerland) is a resin-based sealer widely used for root canal filling due its acceptable physical properties, low solubility and disintegration, apical sealing ability, good adhesion, antimicrobial action, and good biological properties ${ }^{2}$. However, studies have demonstrated $\mathrm{AH}$ Plus higher cytotoxic effects compared to MTA-based sealer ${ }^{30}$. MTA Fillapex (Angelus Dental Solutions, Londrina, PR, Brazil) is a calcium silicate-based root canal sealer that contains salicylate resin, diluting resin, natural resin, bismuth oxide, nanoparticulate silica, and MTA. It was developed to utilize the good features of MTA; relatively high levels of biocompatibility, antimicrobial activity, and sealing ability have been reported for this material ${ }^{1}$.

Adhesion and penetration are two important aspects to be considered in sealer selection. Adhesion of an endodontic sealer is defined as its capacity to adhere to root canal walls and promote the union of guttapercha cones to each other and to the dentin ${ }^{2,26}$. Sealer penetration into dentinal tubules is also a required feature, as it can improve the connection between sealer and dentin ${ }^{13}$. The penetration ability of root canal filling materials with antibacterial effect into dentinal tubules may also help avoiding colonization by residual bacteria and root canal reinfection ${ }^{1,6}$.

Studies have shown that bond strength and sealer penetration may be affected by the pretreatment of root canal walls and by the type of sealer used2,11,21. Regarding the effects of auxiliary technologies used for root canal disinfection, photoactivated disinfection does not adversely affect the bond strength of AH Plus to dentin, but it has a negative effect on MTA Fillapex sealer $^{17,18}$.

This study assessed the effects of photodynamic therapy (PDT) and non-thermal plasma (NTP) on adhesion and sealer penetration in root canals filled with $\mathrm{AH}$ Plus and MTA Fillapex and the correlation between adhesion and sealer penetration.

\section{Material and Methods}

\section{Specimen preparation}

Sixty straight single-rooted premolar teeth were used. Teeth with a fully formed apex were selected, whereas roots with resorption defects, fractures, or open apices were excluded. Crowns were sectioned below the cemento-enamel junction so that the lengths of all roots were adjusted to $14 \mathrm{~mm}$ using a low-speed diamond saw (Isomet; Buehler Ltd, Lake Bluff, IL, USA) under water cooling. Patency of each root canal was checked using a size $10 \mathrm{~K}$-file (Dentsply Maillefer, Ballaigues, Switzerland) and working length (WL) was established at $1 \mathrm{~mm}$ short of the apex. All teeth had their apices sealed with utility wax (Technew, Rio de Janeiro, RJ, Brazil) to prevent flow through them.

Cleaning and shaping were performed with a crowndown technique, using Miltex nickel-titanium rotary instruments (Integra ${ }^{\circledR}$ Miltex $^{\circledR}$, York, PA, USA). The following sequence was used: $35 / .10$ to prepare the middle-coronal third. The sequence used in the apical third was: 20/.03; 15/.05; 22/.04; 25/.04; 20/.06; and 20/.07. All files reached the WL. Canals were irrigated with $1 \mathrm{~mL}$ of $5.25 \%$ sodium hypochlorite (Mil Fórmulas, Rio de Janeiro, RJ, Brazil) between each file change. The smear layer was removed after instrumentation with $3 \mathrm{~mL}$ of $17 \%$ EDTA (Maquira Indústria de Produtos Odontológicos Ltda, Londrina, PR, Brazil), $1 \mathrm{~mL}$ per minute. Thereafter, the roots were irrigated with 1 $\mathrm{mL}$ of distilled water to remove EDTA, followed by 1 $\mathrm{mL}$ of sodium hypochlorite. Finally, the root canals were flushed with $5 \mathrm{~mL}$ of distilled water and dried with medium paper points (Endo Points, Manacapuru, AM, Brazil). The teeth were divided into three groups $(n=20)$ : control (no employment of auxiliary technology used for root canal disinfection), PDT, and NTP.

\section{Photodynamic therapy}

For photodynamic therapy (PDT), after being prepared as described above, the root canals were filled with $15 \mu \mathrm{g} / \mathrm{mL}$ of methylene blue. The solution 
was then stirred with a sterile \#15 K-file (Dentsply Maillefer, Ballaigues, Switzerland) and allowed to stand for $2 \mathrm{~min}$ in the root canal (pre-irradiation time). A diode laser (Twin laser, MMOptics, São Carlos, SP, Brazil) was used as a radiation source with total power of $100 \mathrm{~mW}$ and wavelength of $660 \mathrm{~nm}$. Optical fiber was initially inserted up to the $\mathrm{WL}$, and spiral movements, from apical to coronal, were performed to allow for adequate distribution of light throughout the root canal. Total irradiation time was $90 \mathrm{~s}$, resulting in an energy of $8 \mathrm{~J}$ for each sample, as described by Oliveira, et al. ${ }^{19}$ (2015).

\section{Plasma therapy}

A non-thermal atmospheric pressure plasma jet (Plasma Pen ${ }^{\mathrm{TM}}$, PVA Tepla America, Corona, CA, USA) and a mixture of helium and oxygen ( $98 \% \mathrm{He}$ and $2 \%$ $\mathrm{O}_{2}$, White Martins, Rio de Janeiro, RJ, Brazil) was used. The gas pressure was kept at 6 bar and $1000 \mathrm{~V}$ was applied to generate plasma.

During treatment, the distance between the tip of the plasma jet and the sample was approximately 5 $\mathrm{mm}$. The teeth were exposed to the plasma for $1 \mathrm{~min}$.

\section{Root canal filling}

In control and experimental groups (after photodynamic or plasma therapy), all roots were immediately filled with gutta-percha cones (medium, Microtipped, Endo Points, Manacapuru, AM, Brazil) and AH Plus (Dentsply, Petropolis, RJ, Brazil) or MTA Fillapex (Angelus, Londrina, PR, Brazil) sealers, a total of 6 subgroups $(n=10)$, i.e., control AH Plus, control MTA Fillapex, PDT AH Plus, PDT MTA Fillapex, NTP AH Plus, and NTP MTA Fillapex.

For confocal laser scanning microscopy, each sealer was fluorescently labeled by adding rhodamine B (Sigma-Aldrich, St. Louis, Missouri, USA) at an approximate ratio of $0.1 \mathrm{w} / \mathrm{w} \%{ }^{20}$. Both sealers were mixed according to the manufacturer's instructions. A gutta-percha cone covered with sealer was introduced into the root canal. Another medium cone was further used as accessory until the entire length of the root canal was filled. A \#45 McSpadden condenser (Dentsply Maillefer, Ballaigues, Switzerland) was then used. The plugger was advanced apically up to $4 \mathrm{~mm}$ from the apical stop and slowly removed. Afterwards, the plugger was removed slowly whilst being pushed softly against one side of the canal. Roots were sealed with provisional restorative material (Cavitec, Caitech
Produtos Odontológicos, Rio do Sul, SC, Brazil). Specimens were kept in an incubator at $37^{\circ} \mathrm{C}$ and $100 \%$ humidity for 2 days.

\section{Push-out test}

Each root was horizontally sectioned with a slowspeed water-cooled diamond saw (Buehler Isomet 2000, Lake Bluff, IL, USA) at 4, 8, and $12 \mathrm{~mm}$ from the apex ${ }^{14}$ to produce $1-\mathrm{mm}$ thick slices for each root region (apical, middle, and coronal).

Loading was performed using an electromechanical machine (EMIC DL200MF, São José dos Pinhais, PR, Brazil) at a crosshead speed of $0.5 \mathrm{~mm} / \mathrm{min}$ until bond failure occurred. Three tips with different diameters were used for load application in the push-out test in the different thirds $(0.76 \mathrm{~mm}$ for cervical third, $0.60 \mathrm{~mm}$ for middle third, and $0.40 \mathrm{~mm}$ for apical third). Debonding values (maximum load) were used to calculate the push-out strength in megapascals (MPa), according to the following formula:

Push-out bond strength $(\mathrm{MPa})=$

$$
\frac{\text { Maximum load }(\mathrm{N})}{\text { Adhesion area }\left(\mathrm{mm}^{2}\right)}
$$

The adhesion area was calculated by using the following formula: $A=\pi(R+r)\left[\left(h^{2}+(R-r)^{2}\right]^{0.5}\right.$

where $n=3.14, R$ is the coronal side radius, $r$ is the apical side radius, and $\mathrm{h}$ is the thickness of the slice.

The thickness of each slice was measured using a digital caliper (Vonder, Curitiba, PR, Brazil) and the coronal and apical radii were measured using a stereoscope (Leika MZ75, Meyer Instruments, Houston, TX, USA) and IM50 software (Leika IM50 Image manager, Houston, TX, USA).

\section{Confocal microscopy}

After the push-out test, the remaining gutta-percha was removed and the sections were polished manually with wet 1200-, 2400- and 4000-grit silicon carbide (SiC) abrasive paper (Carbimet Disc Set, Buehler, Lake Bluff, IL, USA). For each abrasive paper, the sections were polished for $1 \mathrm{~min}$.

Specimens were mounted onto glass slides and examined under a confocal laser scanning microscope (Leica Microsystems GmbH, Mannheim, Germany) using a 5x objective (Leica Microsystems $\mathrm{GmbH}$, Mannheim, Germany). Absorption and emission wavelengths for rhodamine-B were set to 540 and $590 \mathrm{~nm}$. Images from each section were taken at a resolution of $1,024 \times 1,024$ pixels. 
Image analysis was performed using Adobe Photoshop (Adobe Systems Incorporated, San Jose, CA, USA). Six images were compiled to create an image with the whole tooth. First, confocal microscopy images of the slice were chosen (Figure $1 \mathrm{~A}$ ). Then, the image of the slice captured with the stereoscope was selected (Figure 1B), creating the final image (Figure $1 \mathrm{C}$ ).

To calculate maximum penetration, measurements of the penetration areas were recorded on the slice (Figure 1D) and maximum penetration was registered (green line) (Figure 1E). For average penetration depth, four points were selected (Figure 1F) and sealer penetration was registered (green line) (Figure $1 \mathrm{G})$. Total perimeter of the root canal (Figure $1 \mathrm{H}$ ) was measured and the penetrated perimeter registered (green line) (Figure 1I). As to the penetrated area, first the total area of the slice (Figure $1 \mathrm{~J}$ ) was assessed and then the sealer penetrated area was calculated (Figure 1K) $)^{5,8}$.

\section{Statistical analysis}

The Kolmogorov-Smirnov test was used to assess the normality of data. Since data were not normally distributed, the Kruskal-Wallis test was used for general comparison and Dunn's test for pairwise comparison. The Spearman's test was used to correlate data. The significance level was set at $5 \%$.

\section{Results}

Table 1 shows the median bond strength values (MPa) for both sealers. Plasma therapy results were similar to the control group, whereas PDT presented significantly low strength when $\mathrm{AH}$ Plus was used. Conversely, both therapies showed lower bond strength than the control group using MTA Fillapex.

Figure 2 and 3 show representative confocal images of the different groups for AH Plus and MTA Fillapex

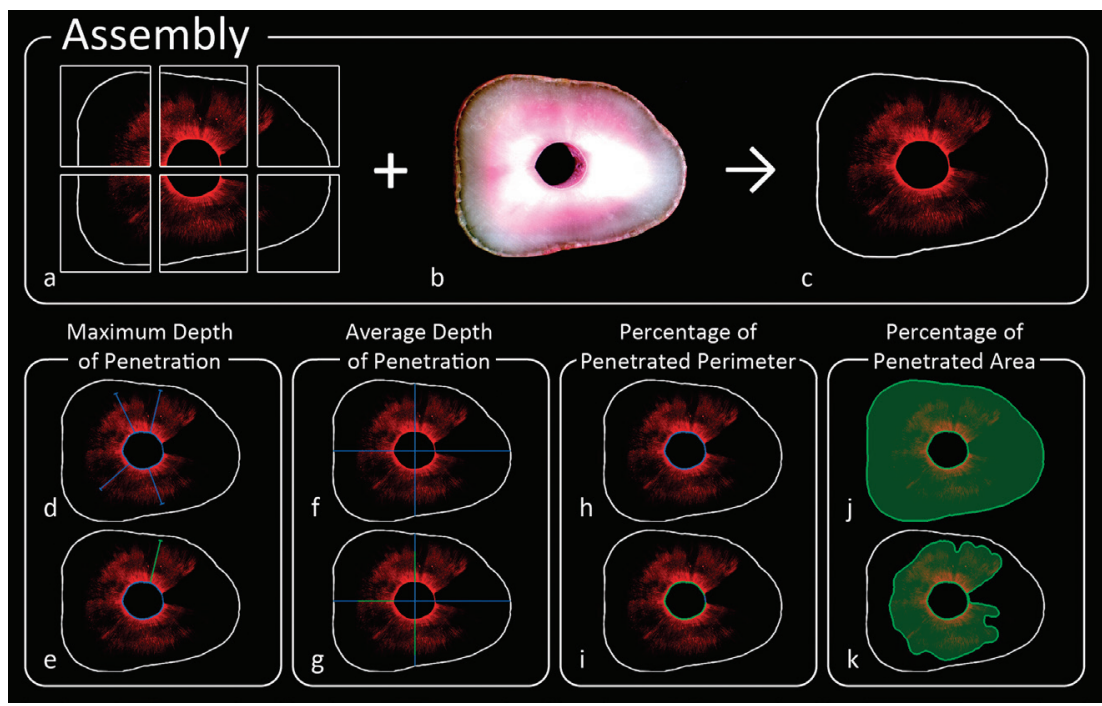

Figure 1- Experimental design: (A) Selection of confocal microscopy images of the chosen slice; (B) Selection of slice image captured with stereoscope; (C) Final image; (D) Maximum penetration into the slice; (E) Selection of the registered maximum penetration (green line); $(F)$ Selection of four points for average penetration depth; $(G)$ Registration of penetration (green line); (H) Measurement of the total perimeter of the canal; (I) Measurement of penetrated perimeter (green line); (J) Total area of the slice; (K) Sealer penetrated area

Table 1- The median bond strength values (MPa) for both sealers

\begin{tabular}{ccccccc}
\hline Section & $\begin{array}{c}\text { Control } \\
(\mathrm{MPa})\end{array}$ & $\begin{array}{c}\text { PH Plus } \\
\text { (MPa) }\end{array}$ & $\begin{array}{c}\text { Plasma } \\
(\mathbf{M P a})\end{array}$ & $\begin{array}{c}\text { Control } \\
(\mathbf{M P a})\end{array}$ & $\begin{array}{c}\text { PDT } \\
(\mathbf{M P a})\end{array}$ & $\begin{array}{c}\text { Plasma } \\
(\mathrm{MPa})\end{array}$ \\
\hline $\begin{array}{c}4 \mathrm{~mm} \text { from the } \\
\text { apex }\end{array}$ & 5.67 & 4.58 & 4.69 & 3.55 & 1.25 & 2.23 \\
\hline $\begin{array}{c}8 \mathrm{~mm} \text { from the } \\
\text { apex }\end{array}$ & 2.99 & 2.26 & 2.42 & 1.66 & 0.19 & 0.30 \\
$\begin{array}{c}12 \mathrm{~mm} \text { from the } \\
\text { apex }\end{array}$ & 3.32 & 2.29 & 3.54 & 2.18 & 0.36 & 0.52 \\
\hline Total & $3.33^{\mathrm{A}}$ & $2.44^{\mathrm{B}}$ & $3.54^{\mathrm{A}}$ & $2.22^{\mathrm{A}}$ & $0.50^{\mathrm{B}}$ & $0.55^{\mathrm{B}}$ \\
\hline
\end{tabular}

\footnotetext{
A, B Comparison between groups of the same sealer (Statistical analysis on the row). Different letters indicate statistically significant values
} 
sealers, respectively.

Table 2 shows median values of maximum and mean sealer penetration depth, penetrated perimeter (\%), and penetrated area (\%) for the AH Plus sealer. Overall, the control group presented statistically higher values than the PDT and the plasma therapy groups for maximum penetration, mean penetration, and penetrated area, which did not differ among groups. Regarding penetrated perimeter, the groups showed similar values. When the segments were separately evaluated and compared with the overall results, those obtained for the coronal and middle thirds ( 8 and 12 $\mathrm{mm}$ from the apex) were similar to the overall analysis. There was no difference among groups for the apical third. After comparing the different segments, the apical third showed similar or lower values compared to the middle and coronal thirds.

Regarding MTA Fillapex, plasma therapy showed better results for all parameters than did the control group. PDT group values were similar to the control group for maximum penetration, mean penetration, and penetrated perimeter and similar to the plasma therapy group for penetrated area. The sealer applied to the apical third did not show differences among groups. After comparing the different segments, the values for the apical third were similar or lower when compared to the other groups.

In the push-out test and confocal analysis, the Spearman's test showed no positive correlation between bond strength and sealer penetration.

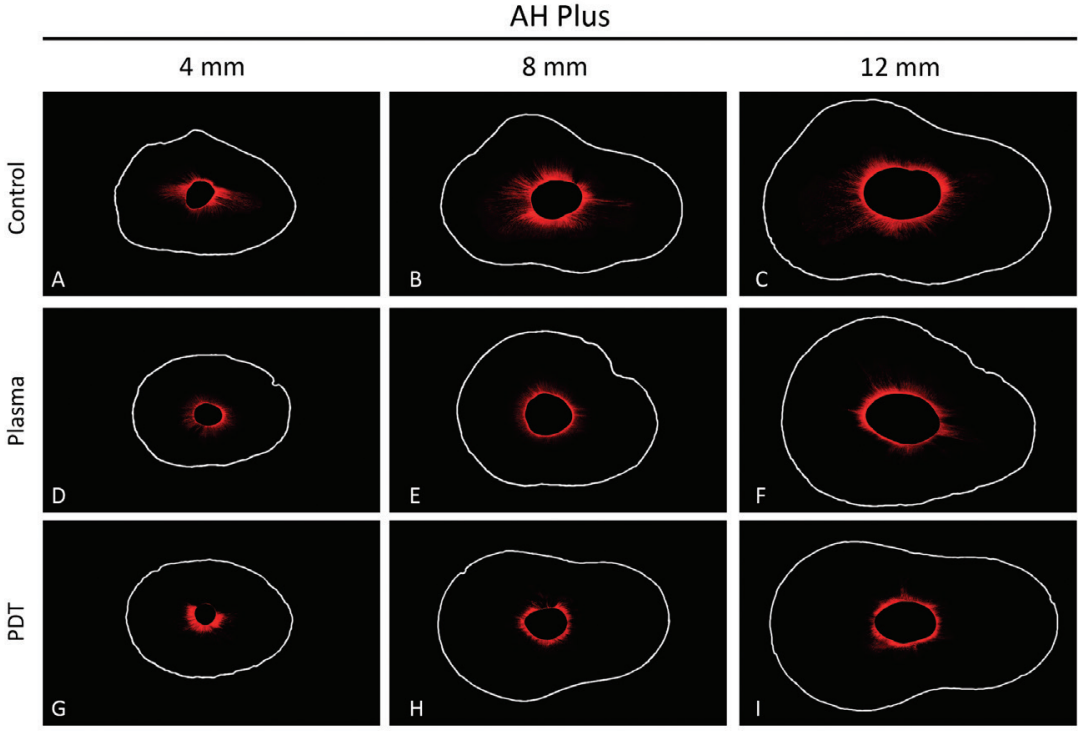

Figure 2- Representative images of confocal for AH Plus sealer

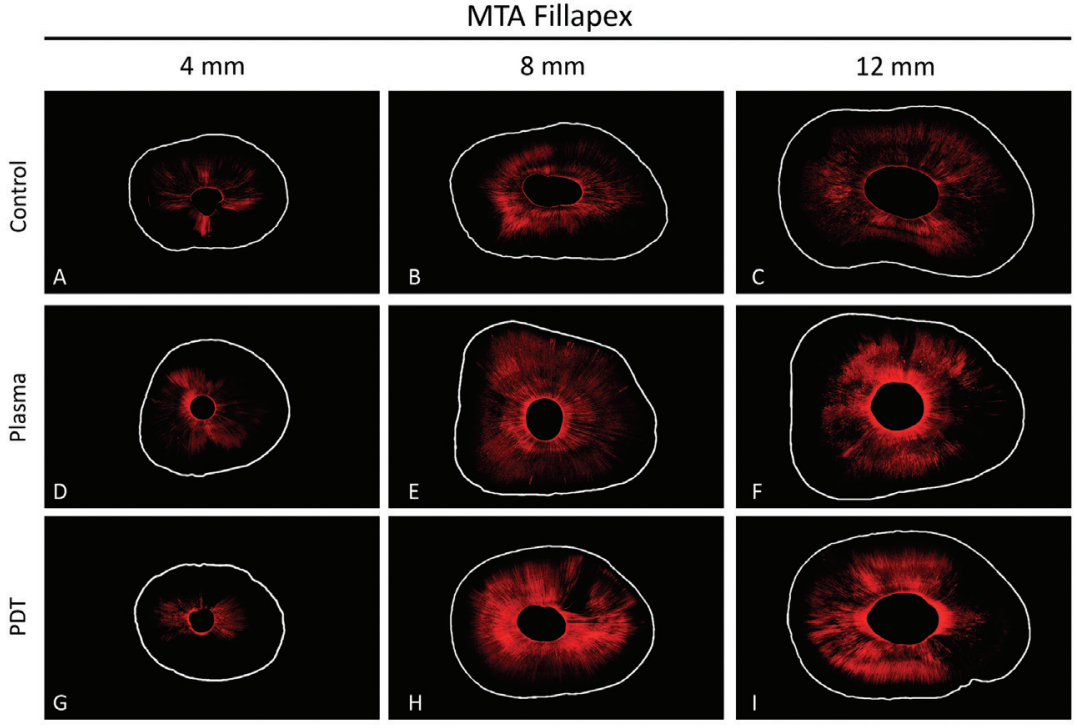

Figure 3- Representative images of confocal for MTA Fillapex sealer 
Table 2- Confocal analysis for AH Plus sealer

\begin{tabular}{|c|c|c|c|c|c|}
\hline & Group & $\begin{array}{l}\text { Maximum depth of } \\
\text { penetration }(\mu \mathrm{m})\end{array}$ & $\begin{array}{c}\text { Mean depth of } \\
\text { penetration }(\mu \mathrm{m})\end{array}$ & $\begin{array}{c}\text { Penetrated } \\
\text { perimeter (\%) }\end{array}$ & $\begin{array}{c}\text { Penetrated area } \\
(\%)\end{array}$ \\
\hline \multirow[t]{3}{*}{ Total } & Control & $1045.95^{A}$ & $594.87^{A}$ & $82.99^{A}$ & $17.76^{A}$ \\
\hline & PDT & $613.04^{B}$ & $389.77^{B}$ & $98.95^{\mathrm{A}}$ & $11.18^{B}$ \\
\hline & Plasma & $581.25^{\mathrm{B}}$ & $398.85^{\mathrm{B}}$ & $100.00^{A}$ & $14.95^{\mathrm{B}}$ \\
\hline \multirow{3}{*}{$\begin{array}{l}4 \mathrm{~mm} \text { from the apex } \\
\text { (apical) }\end{array}$} & Control & $632.71^{\mathrm{Ab}^{*}}$ & $357.23^{\mathrm{Ab}^{*}}$ & $61.80^{A b^{*}}$ & $14.10^{\mathrm{Ab}^{*}}$ \\
\hline & PDT & $541.90^{\text {Aa• }}$ & $284.95^{\mathrm{Ab} \cdot}$ & $58.18^{\mathrm{Ab} \cdot}$ & $12.02^{\mathrm{Aa} \cdot}$ \\
\hline & Plasma & $505.57^{\text {Aas }}$ & $295.17^{\text {Aa }}$ & $83.96^{\mathrm{Ab}}$ & 16.36 \\
\hline \multirow{3}{*}{$\begin{array}{l}8 \mathrm{~mm} \text { from the apex } \\
\text { (middle) }\end{array}$} & Control & $1192.77^{\mathrm{Aa}^{*}}$ & $574.44^{\mathrm{Aa}^{*}}$ & $82.49^{\mathrm{Aa}^{*}}$ & $19.06^{\mathrm{Aa}^{*}}$ \\
\hline & PDT & $684.18^{\mathrm{Ba} \cdot}$ & $436.32^{\mathrm{Aa} \cdot}$ & $99.37^{\mathrm{Aa} \cdot}$ & $11.25^{\mathrm{Ba} \cdot}$ \\
\hline & Plasma & $543.41^{\mathrm{Ba}}$ & $417.02^{\mathrm{Aa}}$ & $100.00^{\mathrm{Aab}}$ & $15.28^{\mathrm{ABa}}$ \\
\hline \multirow{3}{*}{$\begin{array}{l}12 \mathrm{~mm} \text { from the } \\
\text { apex (coronal) }\end{array}$} & Control & $1154.93 \mathrm{Aa}^{*}$ & $750.78^{\mathrm{Aa}^{*}}$ & $100.00^{\mathrm{Aa}^{*}}$ & $25.42^{\mathrm{Aa}^{*}}$ \\
\hline & PDT & $641.80^{\mathrm{Ba} \cdot}$ & $418.91^{\mathrm{Ba} \cdot}$ & $100.00^{\mathrm{Aa} \cdot}$ & $9.18^{\mathrm{Ba} \cdot}$ \\
\hline & Plasma & $664.50^{\mathrm{Ba}}$ & $448.43^{\mathrm{Ba}}$ & $100.00^{\text {Aa }}$ & $9.90^{\mathrm{Ba}}$ \\
\hline
\end{tabular}

$(A, B)$ Comparison between groups; $(a, b)$ comparison between segments in the same group (control*, PDT•, plasma )

Table 3- Confocal analysis for MTA Fillapex sealer

\begin{tabular}{|c|c|c|c|c|c|}
\hline & Group & $\begin{array}{l}\text { Maximum depth of } \\
\text { penetration }(\mu \mathrm{m})\end{array}$ & $\begin{array}{c}\text { Mean depth of } \\
\text { penetration }(\mu \mathrm{m})\end{array}$ & $\begin{array}{c}\text { Penetrated } \\
\text { perimeter (\%) }\end{array}$ & $\begin{array}{c}\text { Penetrated area } \\
(\%)\end{array}$ \\
\hline \multirow[t]{3}{*}{ Total } & Control & $1,380.47^{\mathrm{B}}$ & $823.44^{\mathrm{B}}$ & $82.86^{\mathrm{B}}$ & $32.58 \mathrm{~B}$ \\
\hline & PDT & $1,398.63^{\mathrm{B}}$ & $927.50^{\mathrm{B}}$ & $91.85^{A}$ & $40.61^{\mathrm{B}}$ \\
\hline & Plasma & $1,645.36^{A}$ & $1,290.03^{A}$ & $100.00^{A}$ & $61.13^{\mathrm{A}}$ \\
\hline \multirow{3}{*}{$\begin{array}{l}4 \mathrm{~mm} \text { from the apex } \\
\text { (apical) }\end{array}$} & Control & $997.51^{\mathrm{Aa}^{*}}$ & $662.23^{\mathrm{Aa}^{*}}$ & $75.53^{\mathrm{Aa}^{*}}$ & $20.73^{\mathrm{Aa}^{*}}$ \\
\hline & PDT & $1,147.36^{\mathrm{Aa} \cdot}$ & $576.71^{\text {Aa॰ }}$ & $68.02^{\mathrm{Aa} \cdot}$ & $18.76^{\text {Aa• }}$ \\
\hline & Plasma & $1,268.46^{\mathrm{Ab}}$ & $885.12^{\mathrm{Ab}}$ & $95.54^{\mathrm{Aa}}$ & $42.48^{\mathrm{Ab}}$ \\
\hline \multirow{3}{*}{$\begin{array}{l}8 \mathrm{~mm} \text { from the apex } \\
\text { (middle) }\end{array}$} & Control & $1,545.46^{\mathrm{Aa}^{*}}$ & $937.72^{\mathrm{Ba}^{*}}$ & $96.31^{\mathrm{Aa}^{*}}$ & $41.94^{\mathrm{Ba}^{*}}$ \\
\hline & PDT & $1,910.25^{\text {Aa }}$ & $1,163.26^{\text {АВа॰ }}$ & $91.16^{\mathrm{Aa} \cdot}$ & $49.39^{\text {АВа }}$ \\
\hline & Plasma & $1,884.52^{\mathrm{Aa}}$ & $1,350.20^{\text {Aa }}$ & $100.00^{\text {Aas }}$ & $67.06^{\text {Aas }}$ \\
\hline \multirow{3}{*}{$\begin{array}{l}12 \mathrm{~mm} \text { from the } \\
\text { apex (coronal) }\end{array}$} & Control & $1,471.29^{\mathrm{Aa}^{*}}$ & $868.09^{\mathrm{Ba}^{*}}$ & $88.47^{\mathrm{Ba}^{*}}$ & $30.99^{\mathrm{Ba}^{*}}$ \\
\hline & PDT & $1,454.64^{\mathrm{Aa} \cdot}$ & $921.83^{\mathrm{Aa}}$ & $99.05^{\mathrm{ABa} \cdot}$ & $46.29^{\mathrm{ABa} \cdot}$ \\
\hline & Plasma & $1,886.04^{\text {Aat }}$ & $1,457.29^{\text {Aa }}$ & $100.00^{\text {Aas }}$ & $63.63^{\text {Aas }}$ \\
\hline
\end{tabular}

$(A, B)$ Comparison between groups; $(a, b)$ comparison between segments in the same group (control*, PDT•, plasma )

\section{Discussion}

PDT and plasma therapy have been proposed as auxiliary therapy in chemomechanical preparation due to their antimicrobial activity $7,15,20,27,28$. Both technologies create reactive oxygen species, causing serious damage to microorganisms through irreversible oxidation of cell components ${ }^{12,19,25}$. The effects of these therapies have been studied in different periods of

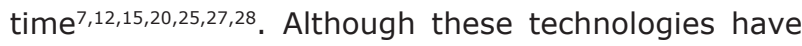
shown favorable results concerning their antimicrobial activity, little is known about their impact on adhesion and sealer penetration.

In the present study, PDT was applied for $90 \mathrm{~s}$. This period was chosen because it was the minimum period found in the literature that antimicrobial activity was verified by the same parameters employed in the present study ${ }^{12,19,25}$.

A mixture of helium and oxygen (98\% He and $2 \%$ $\mathrm{O}_{2}$ ) was applied for $60 \mathrm{~s}$ for its antimicrobial properties. Also, this mixture has non-thermal characteristics acting at room temperature and causing no damage to periapical and periodontal tissues. Additionally, short periods are clinically favorable.

Flow and adhesion are essential properties when choosing the proper endodontic sealer. Flow allows adequate penetration of the sealer into the dentinal tubules and may favor contact and confinement of microorganisms to the dentinal tubules, providing better antiseptic action. Adequate flow ability allows filling irregularities, isthmuses, and accessory canals. Adhesion allows the material to remain on the walls, 
thus aiding stability of the filling mass and preventing microleakage ${ }^{24}$. The present study evaluated the effect of PDT and plasma therapy on adhesion and sealer penetration using two sealers - a resin-based sealer (AH Plus) and an MTA-based sealer (MTA Fillapex). Sealers were also compared for each third and adhesion and sealer penetration were correlated.

With respect to AH Plus, plasma therapy adhesion was similar to the control group, while PDT yielded significantly lower values. An explanation for the poor results of PDT would be the possible interference/ remnants of the photosensitizing agent on the dentin surface. On the other hand, plasma therapy was used in dry root canals and had no influence on adhesion. This result contradicts the findings of Ok, et al. 17,18 $(2013,2014)$, who verified that photoactivated disinfection did not adversely affect bond strength of $\mathrm{AH}$ Plus to the root canal dentin. Different results can be associated with different laser systems, photosensitizing agents, and with the segments selected for the push-out test. Regarding the use of plasma, any study had previously evaluated its effect on adhesion, not allowing comparisons with data from the literature.

PDT and plasma showed low bond strength values for MTA Fillapex compared to the control group, showing the negative effect of these therapies on this sealer adhesion. Our results are consistent with those of Ok, et al. ${ }^{17}$ (2013), who verified that photoactivated disinfection adversely affected bond strength of MTA Fillapex. According to these authors, this might have occurred due the type of photosensitizing agent used.

$\mathrm{AH}$ Plus showed higher bond strength than MTA Fillapex, in line with Sagsen, et al. ${ }^{23}$ (2011). An explanation for the poor adhesion of MTA Fillapex is that the apatite formed by MTA and phosphatebuffered saline may be deposited within collagen fibrils, promoting controlled mineral nucleation on dentin, seen as the formation of an interfacial layer with taglike structures ${ }^{22,23}$. Low bond strength of MTA Fillapex could be due to the low adhesion capacity of these tag-like structures ${ }^{22,23}$. Additionally, throughout the experiment MTA Fillapex showed to be quite friable. However, Assmann, et al. ${ }^{4}$ (2012) found similar bond strength comparing AH Plus and MTA Fillapex.

Sealers were manipulated in association with rhodamine. Bitter, et al. ${ }^{5}$ (2009) associated rhodamine with cements and observed that bond strength values were not affected by rhodamine, values were similar to those reported in the literature. The same occurred in the present study, bond strength values found here were similar to those reported in the literature ${ }^{4,14}$.

$\mathrm{AH}$ Plus sealing ability was statistically higher in the control group than in the PDT and plasma therapy groups regarding maximum penetration, mean penetration, and penetrated area, and both treatments did not differ between themselves. Regarding penetrated perimeter, all groups showed similar values. However, a different behavior was found for MTA Fillapex. Here, plasma therapy had better results for all parameters than the control group. Maximum penetration, mean penetration, and penetrated perimeter were similar in the PDT and control groups, with similar results for penetrated area in the plasma therapy group. Different results can be related to sealer composition and its interaction with the dentin surface, as well as to different viscosity ${ }^{16}$.

MTA Fillapex penetration was better than that of $\mathrm{AH}$ Plus, possibly due to low viscosity and high flow ability of the former ${ }^{3,16}$. These results are in accordance with previous studies ${ }^{10,16}$, however, other studies found similar results when comparing MTA Fillapex and $\mathrm{AH}$ Plus $^{9,24}$.

The use of the two sealers in the apical segment did not show differences among groups. The other thirds results were similar to the overall analysis. This difference can be associated with the penetration depth of PDT and plasma. Regarding PDT, the presence of vapor lock may have hindered the action of the photosensitizing agent ${ }^{29}$. In plasma therapy, anatomical limitations due to the distance between plasma pen and apical third may have prevented the action of plasma on the apical third.

The Spearman's test did not show a positive correlation between adhesion and penetration parameters in any of the sealers studied. Thus, it was verified that while both are important characteristics and the key to root canal filling success $2,6,13,26,30$, good adhesion is not directly correlated with good penetration of AH Plus and MTA Fillapex sealers.

\section{Conclusion}

PDT and plasma therapy affected the adhesion and sealer penetration in root canals filled with $\mathrm{AH}$ Plus and MTA Fillapex. Moreover, no positive correlation between adhesion and sealer penetration was found for $\mathrm{AH}$ Plus 
and MTA Fillapex.

\section{Acknowledgements}

This study was supported by Brazilian agencies Faperj, Capes (PNPD) \& CNPq. The authors deny any conflicts of interest related to this study.

\section{References}

1- Akcay M, Arslan H, Durmus N, Mese M, Capar ID. Dentinal tubule penetration of AH Plus, iRoot SP, MTA fillapex, and guttaflow bioseal root canal sealers after different final irrigation procedures: a confocal microscopic study. Lasers Surg Med. 2016;48:70-6.

2- Alfredo E, Silva SR, Ozório JE, Souza-Neto MD, Brugnera-Júnior A, Silva-Sousa YT. Bond strength of AH Plus and Epiphany sealers on root dentine irradiated with 980 nm diode laser. Int Endod J. 2008;41:73340

3- Amoroso-Silva PA, Guimarães BM, Marciano MA, Duarte MA, Cavenago BC, Ordinola-Zapata $R$, et al. Microscopic analysis of the quality of obturation and physical properties of MTA Fillapex. Microsc Res Tech. 2014;77:1031-6.

4- Assmann E, Scarparo RK, Böttcher DE, Grecca FS. Dentin bond strength of two mineral trioxide aggregate-based and one epoxy resinbased sealers. J Endod. 2012;38:219-21.

5- Bitter K, Paris S, Pfuertner C, Neumann K, Kielbassa AM. Morphological and bond strength evaluation of different resin cements to root dentin. Eur J Oral Sci. 2009;117:326-33.

6- Bouillaguet S, Shaw L, Barthelemy J, Krejci I, Wataha JC. Long-term sealing ability of pulp canal sealer, AH-Plus, GuttaFlow and Epiphany. Int Endod J. 2008;41:219-26.

7- Du T, Ma J, Yang P, Xiong Z, Lu X, Cao Y. Evaluation of antibacterial effects by atmospheric pressure nonequilibrium plasmas against Enterococcus faecalis biofilms in vitro. J Endod. 2012;38:545-9.

8- Gharib SR, Tordik PA, Imamura GM, Baginski TA, Goodell GG. A confocal laser scanning microscope investigation of the epiphany obturation system. J Endod. 2007;33:957-61.

9- Kok D, Rosa RA, Barreto MS, Busanello FH, Santini MF, Pereira JR, et al. Penetrability of AH plus and MTA Fillapex after endodontic treatment and retreatment: a confocal laser scanning microscopy study. Microsc Res Tech. 2014;77:467-71.

10- Kuçi A, Alaçam T, Yavaş O, Ergul-Ulger Z, Kayaoglu G. Sealer penetration into dentinal tubules in the presence or absence of smear layer: a confocal laser scanning microscopic study. J Endod. 2014;40:1627-31.

11- Leal F, Simão RA, Fidel SR, Fidel RA, Prado M. Effect of final irrigation protocols on push-out bond strength of an epoxy resin root canal sealer to dentin. Aust Endod J. 2015;41:135-9.

12- Liu CT, Wu CJ, Yang YW, et al. Atomic oxygen and hydroxyl radical generation in round helium-based atmospheric-pressure plasma jets by various electrode arrangements and its application in sterilizing Streptococcus mutans. IEEE Trans Plasma Sci. 2014;42:3830-6.

13- Mamootil K, Messer HH. Penetration of dentinal tubules by endodontic sealer cements in extracted teeth and in vivo. Int Endod J. $2007 ; 40: 873-81$
14- Mokhtari H, Rahimi S, Forough Reyhani M, Galledar S, Mokhtari Zonouzi HR. Comparison of push-out bond strength of gutta-percha to root canal dentin in single-cone and cold lateral compaction techniques with AH Plus sealer in mandibular premolars. J Dent Res Dent Clin Dent Prospects. 2015;9:221-5.

15- Ng R, Singh F, Papamanou DA, Song X, Patel C, Holewa C, et al. Endodontic photodynamic therapy ex vivo. J Endod. 2011;37:217-22. 16- Nikhil V, Bansal P, Sawani S. Effect of technique of sealer agitation on percentage and depth of MTA Fillapex sealer penetration: a comparative in-vitro study. J Conserv Dent. 2015;18:119-23.

17- Ok E, Ertas H, Saygili G, Gok T. Effect of photodynamic therapy on bond strength of root canal filling. J Endod. 2013;39:1428-30.

18- Ok E, Ertas H, Saygili G, Gok T. Effect of photo-activated disinfection on bond strength of three different root canal sealers. Eur J Dent. 2014;8:85-9.

19- Oliveira BP, Aguiar CM, Câmara AC, Albuquerque MM, Correia $A C$, Soares MF. The efficacy of photodynamic therapy and sodium hypochlorite in root canal disinfection by a single-file instrumentation technique. Photodiagnosis Photodyn Ther. 2015;12:436-43.

20- Pan J, Sun K, Liang Y, Sun P, Yang X, Wang J, et al. Cold plasma therapy of a tooth root canal infected with Enterococcus faecalis biofilms in vitro. J Endod. 2013;39:105-10.

21- Prado M, Simão RA, Gomes BP. Effect of different irrigation protocols on resin sealer bond strength to dentin. J Endod. 2013;39:689-92

22- Reyes-Carmona JF, Felippe MS, Felippe WT. Biomineralization ability and interaction of mineral trioxide aggregate and white portland cement with dentin in a phosphate-containing fluid. J Endod. 2009;35:731-6. 23- Sagsen B, Ustün Y, Demirbuga S, Pala K. Push-out bond strength of two new calcium silicate-based endodontic sealers to root canal dentine. Int Endod J. 2011;44:1088-91.

24- Silva RV, Silveira FF, Horta MC, Duarte MA, Cavenago BC, Morais IG, et al. Filling effectiveness and dentinal penetration of endodontic sealers: a stereo and confocal laser scanning microscopy study. Braz Dent J. 2015;26:541-6.

25- Simoncelli E, Barbieri D, Laurita R, Liguori A, Stancampiano A, Viola $L$, et al. Preliminary investigation of the antibacterial efficacy of a handheld Plasma Gun source for endodontic procedures. Clin Plasma Med. 2015;3:77-86.

26- Sousa-Neto MD, Silva Coelho FI, Marchesan MA, Alfredo E, SilvaSousa YT. Ex vivo study of the adhesion of an epoxy-based sealer to human dentine submitted to irradiation with Er:YAG and Nd:YAG lasers. Int Endod J. 2005;38:866-70.

27- Souza LC, Brito PR, Oliveira JC, Alves FR, Moreira EJ, Sampaio-Filho $H R$, et al. Photodynamic therapy with two different photosensitizers as a supplement to instrumentation/irrigation procedures in promoting intracanal reduction of Enterococcus faecalis. J Endod. 2010;36:292-6. 28- Sun K, Yang X, Ye G, Pan H, Wang J. Evaluation of two different cold plasma treatments on root canal infected with Enterococcus faecalis biofilms. Hua Xi Kou Qiang Yi Xue Za Zhi. 2013;31:195-8.

29- Tay FR, Gu LS, Schoeffel GJ, Wimmer C, Susin L, Zhang K, et al. Effect of vapor lock on root canal debridement by using a side-vented needle for positive-pressure irrigant delivery. J Endod. 2010;36:745-50. 30- Zhang W, Li Z, Peng B. Ex vivo cytotoxicity of a new calcium silicatebased canal filling material. Int Endod J. 2010;43:769-74. 